\title{
INFLUÊNCIA DE FATORES ABIÓTICOS NA RESPOSTA DE SEMENTES DE MIMOSA PUDICA A GERMINAÇÃO
}

\author{
Sara Bezerra Bandeira ${ }^{1}$, Amanda Santana de Oliveira ${ }^{2}$, Nádia da Silva Ramos ${ }^{3}$, Marciane Cristina \\ Dotto $^{4}$, Eduardo Andrea Lemus Erasmo ${ }^{5}$
}

\begin{abstract}
RESUMO - O presente trabalho teve como objetivo avaliar os efeitos da quebra de dormência, temperatura, luz e pH sobre a germinação de sementes de Mimosa pudica. Foram realizados dois experimentos, onde no experimento 1 , foram utilizados dois métodos químicos de quebra de dormência, com sementes imersas em hipoclorito de sódio por $0,1,2,4,8,12$ e 16 horas e em ácido sulfúrico $\left(\mathrm{H}_{2} \mathrm{SO}_{4}\right)$ por $0,1,5,10,15$ e 20 minutos. Ambos os tratamentos foram mantidos em BOD com temperatura $28^{\circ} \mathrm{C}$ e fotoperíodo $12 / 12$. Com

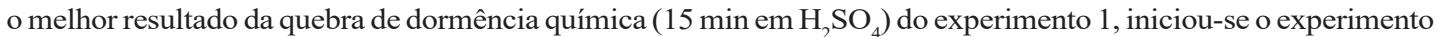
2 , onde as sementes foram imersas por 15 minutos em $\mathrm{H}_{2} \mathrm{SO}_{4}$ e submetidas a seis temperaturas $(20,25,30$, $35,20 / 30,20 / 35 \mathrm{C}^{\circ}$ ). Sendo que essas 6 temperaturas foram mantidas em momentos distintos em três fotoperíodo de 12/12, 8/16 horas (Dia/Noite) e sem luz. Foram avaliados o percentual de germinação e índice de velocidade de germinação. As avaliações da germinação foram feitas diariamente a partir do terceiro dia e estendendo até o décimo quarto dia do experimento. $\mathrm{O}$ hipoclorito de sódio não atuou na quebra de dormência de sementes de M. pudica. Observou-se que a temperatura que proporcionou maior germinação de sementes de M. pudica obtida em ambos os fotoperíodos e no escuro foi $25^{\circ} \mathrm{C}$ e que a espécie é fotoblástica neutra. Não foram observadas variações de germinação de Mimosa pudica em relação ao pH.
\end{abstract}

Palavras chave: emergência, temperatura, fotoperíodo.

\section{INFLUENCE OF ABYOTHIC FACTORS IN THE SEED RESPONSE OF MIMOSA PUDICA GERMINATION}

\begin{abstract}
The present work had the objective of evaluating the effects of dormancy, temperature and light breaking on the germination of Mimosa pudica seeds. In two experiments, two chemical methods of dormancy breaking were used, with seeds immersed in sodium hypochlorite for 0, 1, 2, 4, 8, 12 and 16 hours and in sulfuric acid $\left(\mathrm{H}_{2} \mathrm{SO}_{4}\right)$ for $0,1,5,10,15$ and 20 minutes. Both treatments were maintained in BOD at 28 ${ }^{\circ} \mathrm{C}$ and $12 / 12$ photoperiod. With the best result of the chemical dormancy breaking (15min in $\left.\mathrm{H}_{2} \mathrm{SO}_{4}\right)$ of experiment 1, the experiment 2 was started, where the seeds were immersed for 15 minutes in $\mathrm{H}_{2} \mathrm{SO}_{4}$ and submitted to 6 temperatures $\left(20,25,30,35,20 / 30,20 / 35^{\circ} \mathrm{C}\right)$. These six temperatures were maintained at different times in three photoperiod of 12/12, 8/16 hours (Day / Night) and without light. The percentage of germination and rate of germination were evaluated. The germination evaluations were done daily from the third day and extended until the fourteenth day of the experiment. Sodium hypochlorite did not act on seed dormancy of M. pudica. It was observed that the best seed germination temperature of M. pudica obtained in both photoperiods and in the dark was $25^{\circ} \mathrm{C}$ and that the species is photoblastic neutral. No variations of Mimosa pudica germination were observed with respect to $\mathrm{pH}$.
\end{abstract}

Keywords: emergency, temperature, photoperiod.

\footnotetext{
${ }^{1}$ Doutoranda em Engenharia Florestal, Universidade Federal de Lavras; *Autor para correspondência: sarabbandeira@mail.uft.edu.br.

${ }^{2}$ Engenheira Agrônoma, Universidade Federal do Tocantins, Campus Gurupi.

${ }^{3}$ Doutoranda em Produção Vegetal, Universidade Federal do Tocantins, Campus Gurupi.

${ }^{4}$ Docente no Ensino Básico e Tecnológico do Instituto Federal do Tocantins, Campus Dianópolis

${ }^{5}$ Docente do curso de Pós-Graduação em Produção Vegetal da Universidade Federal do Tocantins, Campus de Gurupi.
} 


\section{INTRODUÇÃO}

A Mimosa pudica é uma espécie típica da região tropical, ocorre em grande parte do território brasileiro, havendo maior concentração na Região Central, em áreas de Cerrado. É uma espécie muito agressiva, com sementes capazes de germinar em condições extremas (alto teor de salinidade, elevado estresse hídrico e em profundidades de até 6 centímetros), suas sementes apresentam dormência exógena, do tipo física e são tolerantes a sombra, constituindo problema como infestante tanto em culturas perenes como anuais (Chauhan e Johnson, 2009).

O manejo de plantas daninhas corresponde a um dos principais fatores do custo de produção, sendo indispensável para a obtenção de maiores produtividades e elevação na qualidade de frutos (Ronchi et al., 2010).

Estudos básicos sobre biologia germinativa de plantas daninhas são muito importantes, pois a partir disso é possível interpretar o comportamento ecológico das espécies que infestam áreas tropicais e subtropicais, podendo auxiliar na construção de estratégias adequadas para seu manejo, e ainda pode contribuir para o desenvolvimento de métodos de controle em áreas cultivadas (Canossa et al., 2007a).

O processo germinativo resulta do balanço entre condições ambientais favoráveis, sendo que cada espécie vegetal apresenta um conjunto de requisitos específicos quanto à disponibilidade de água, temperatura, luz e $\mathrm{pH}$, para a ocorrência do processo de germinação (Mondo et al., 2010; Guillemin et al., 2013).

A temperatura determina a taxa de germinação, tendo em vista que, em temperatura ótima há uma maior porcentagem de germinação em menor espaço de tempo, já em temperaturas máximas e mínimas pode haver uma menor porcentagem de germinação ou a morte do embrião (Carvalho \& Nakagawa, 2012).

A presença de luz também desempenha papel importante nos processos de dormência/germinação, tanto a intensidade, o comprimento de onda, quanto o fotoperíodo, são variáveis conhecidas por exercerem efeito sobre a germinação de plantas daninhas, porém esse efeito é dependente da espécie (Mondo et al., 2010; Orzari et al., 2013; Bastiani et al., 2015; Jarreta Jr \& Segato, 2016).

A capacidade das plantas suportarem às variações de $\mathrm{pH}$ do meio em que estas se desenvolvem pode ser variável de acordo com a espécie. Alguns trabalhos descrevem o efeito de $\mathrm{pH}$ na germinação de sementes de plantas infestantes, havendo espécies que germinam em amplos gradientes de $\mathrm{pH}$, como Ipomea asarifolia (Souza Filho et al., 2001), Rottboellia exaltata L.f (Monquero et al., 2012) e Campisis radicans (Chachalis; Reddy, 2000) e outras cuja variação de $\mathrm{pH}$ prejudica a germinação das sementes, como Emilia sonchifolia (Yamashita et al., 2009) e Conyza canadensis (Nandula et al., 2006).

A compreensão das limitações na germinação e das características de cada espécie contribui significativamente para as técnicas de controle e manejo a serem utilizadas. Assim, o percentual de emergência de plântulas em pré-semeadura das culturas pode ser reduzido pelas práticas de manejo e, assim, suprimir as infestações e o banco de diásporos da espécie. Já a distribuição espacial das sementes no perfil do solo pode determinar a intensidade de emergência na fase inicial de desenvolvimento da cultura ou, ainda, simular práticas agrícolas (Gazola-Neto et al., 2015).

Existem poucos trabalhos na literatura analisando a eficácia do controle da espécie (Mimosa pudica) e as recomendações são feitas com base nas informações de doses registradas por agentes comerciais (Paula, 2013). Portanto, considerando que Mimosa pudica se trata de uma invasora com capacidade competitiva, informações referentes à sua biologia são de grande interesse, pois contribuem para o desenvolvimento de programas de controle eficientes, a exemplo das informações relativas ao processo germinativo.

Devido os estudos sobre o mecanismo de germinação e fatores influentes na emergência desta invasora serem escassos, objetivou-se com o presente trabalho avaliar os efeitos da quebra de dormência, luz, temperatura e $\mathrm{pH}$ sobre a germinação de sementes de Mimosa. pudica.

\section{MATERIALE MÉTODOS}

O presente estudo foi conduzido no Laboratório de Sementes de Ecofisiologia e Manejo de Plantas Daninhas da Universidade Federal do Tocantins, Campus Universitário de Gurupi, localizado na região sul do Estado do Tocantins a $280 \mathrm{~m}$ de altitude, sob as coordenadas $11^{\circ} 43^{\prime} \mathrm{S}$ e $49^{\circ} 04^{\prime} \mathrm{W}$.

As sementes de Mimosa pudica foram colhidas no início do segundo semestre de 2013, no Campus 
Universitário de Gurupi, em sub-bosque de cultivos de Jatropha curcas (pinhão manso). Após o beneficiamento das sementes, estas foram separadas, selecionadas e submetidas aos tratamentos de superação da dormência.

Para os experimentos de quebra de dormência, de luz e temperatura, as sementes foram colocadas para germinar em placas de Petri sobre duas folhas de papel para germinação umedecidas com água quando submetidas à superação de dormência, luz e temperatura e com cada solução (de acordo com os tratamentos de $\mathrm{pH}$ ), na proporção de 2,5 vezes a massa do substrato seco (Brasil, 2009). Para a limpeza das sementes, as mesmas foram imersas em hipoclorito de sódio a 2,5\% durante 10 minutos e depois foram lavadas com água destilada.

Para todos os experimentos foi utilizado o delineamento inteiramente casualizado com 4 repetições de 50 sementes em cada unidade experimental. Para a análise estatística, os dados foram submetidos a análise de variância através do Software Sisvar e comparadas pelo teste Tukey a 5\% de probabilidade (Ferreira et al., 2014).

\section{Quebra de dormência}

Para o ensaio de quebra de dormência, os testes constituíram-se de:

Escarificação de sementes de $M$. pudica com ácido sulfúrico $\left(\mathrm{H}_{2} \mathrm{SO}_{4}\right)$ : sementes de $M$. pudica foram imersas em uma solução de $\mathrm{H}_{2} \mathrm{SO}_{4}(98 \%)$, por diferentes intervalos de tempo. Os tratamentos testados foram: 1 - Sementes sem imersão na solução de $\mathrm{H}_{2} \mathrm{SO}_{4} ; 2$ sementes imersas na solução de $\mathrm{H}_{2} \mathrm{SO}_{4}$ durante 1 minuto; 3 - sementes imersas na solução de $\mathrm{H}_{2} \mathrm{SO}_{4}$ durante 5 minutos; 4 - sementes imersas na solução de $\mathrm{H}_{2} \mathrm{SO}_{4}$ durante 10 minutos; 5 - sementes imersas na solução de $\mathrm{H}_{2} \mathrm{SO}_{4}$ durante 15 minutos e 6 - sementes imersas na solução de $\mathrm{H}_{2} \mathrm{SO}_{4}$ durante 20 minutos.

Escarificação de sementes de M. pudica com hipoclorito de sódio ( $\mathrm{NaClO}$ ):sementes de Mimosa pudica foram imersas em uma solução de Hipoclorito de Sódio $(2,5 \%)$ por diferentes intervalos de tempo. Os tratamentos testados corresponderam a: 1 - Sementes sem imersão na solução de $\mathrm{NaClO} ; 2$ - sementes imersas na solução de $\mathrm{NaClO}$ durante 1 hora; 3 - sementes imersas na solução de $\mathrm{NaClO}$ durante 2 horas; 4 - sementes imersas na solução de $\mathrm{NaClO}$ durante 4 horas; 5 - sementes imersas na solução de $\mathrm{NaClO}$ durante 8 horas; 6 - sementes imersas na solução de $\mathrm{NaClO}$ durante 12 horas; 7 sementes imersas na solução de $\mathrm{NaClO}$ durante 16 horas.

Depois de realizados os tratamentos de quebra de dormência, as placas foram armazenadas em germinadores tipo B.O.D. regulada a temperatura constante de $28^{\circ} \mathrm{C}$ e fotoperíodo de 12/12.

\section{Luz e temperatura}

Com o resultado da quebra de dormência foi realizado o experimento avaliando a luz e temperatura. Foi estudada a germinação de sementes de Mimosa pudica em esquema fatorial $6 \times 3$, sendo o primeiro fator os seis regimes térmicos (temperaturas constantes de $20,25,30$ e $35^{\circ} \mathrm{C}$ e temperaturas alternadas de $20 / 30$ e $20 / 35^{\circ} \mathrm{C}$ ) e segundo as três condições de luminosidade (fotoperíodos de $8 / 16,12 / 12$ horas diurna/noturna e totalmente no escuro). No caso das temperaturas alternadas o período escuro coincidiu com as menores temperaturas.

Para simular o escuro as placas de Petri foram envolvidas por duas folhas de papel alumínio, tendose o cuidado para impedir o contato das sementes com a luz, inclusive durante a instalação e nas avaliações do experimento, as quais foram realizadas em sala fechada, com luz verde.

Em todos os experimentos, as avaliações foram feitas diariamente a partir do terceiro dia após o estabelecimento dos tratamentos, usando como critério a protrusão da radícula $(2 \mathrm{~mm})$, até que não foi mais observada germinação em nenhum dos tratamentos (Duran \& Tortosa, 1985).

\section{pH e temperatura}

Os tratamentos correspondem a cinco níveis de $\mathrm{pH}(3,0 ; 5,0 ; 7,0 ; 9,0 ;$ e 11,0$)$ e cinco temperaturas $(20$, $25,30,35$ e $20 / 30{ }^{\circ} \mathrm{C}$ ). Para ajustar o $\mathrm{pH}$ foi utilizado hidróxido de potássio $(\mathrm{KOH})$ e ácido clorídrico $(\mathrm{HCl})$ à água destilada, em quantidade suficiente para elevar ou baixar o $\mathrm{pH}$, sendo aferido com auxílio de um $\mathrm{pHmetro}$ (Mayeux \& Scifres, 1978).

Após as avaliações, calculou-se a porcentagem de germinação e o índice de velocidade de germinação (IVG) através da fórmula de Maguire (1962):

$$
\mathrm{IVG}=\mathrm{G}_{1} / \mathrm{N}_{1}+\mathrm{G}_{2} / \mathrm{N}_{2}+\ldots+\mathrm{G}_{\mathrm{n}} / \mathrm{N}_{\mathrm{n}}
$$

onde: $\mathrm{G}_{1}, \mathrm{G}_{2}, \mathrm{G}_{\mathrm{n}}=$ número de plântulas germinadas na primeira, segunda, até a última contagem e $\mathrm{N}_{1}, \mathrm{~N}_{2}, \mathrm{~N}_{\mathrm{n}}=$ 
número de dias avaliados, desde o primeiro, segundo, até o último dia de contagem.

Foi observada diariamente a germinação, a partir do terceiro dia após as sementes serem submetidas aos tratamentos, usando como critério a protrusão da radícula $(2 \mathrm{~mm})$. As variáveis analisadas foram porcentagem de germinação (\%) e índice de velocidade de germinação (IVG). As velocidades de germinação foram calculadas pela expressão (Autor, ano):

$$
I V G=\left(\frac{G 1}{N 1}\right)+\left(\frac{G 2}{N 2}\right)+\ldots+\left(\frac{G n}{N n}\right)
$$

Onde:

G: número de plântulas normais computadas na primeira contagem, na segunda contagem, ..... na iésima contagem.

$\mathrm{N}$ : número de dias da semeadura à primeira, à segunda, ..., à última contagem.

\section{RESULTADOS E DISCUSSÃO}

\section{Quebra de dormência}

Os dados de germinação apresentaram diferença estatística quando comparados ao tratamento 0 , que obteve o menor valor de germinação $-25.33 \%$ (Tabela 1). Os tratamentos em que as sementes ficaram imersas durante 15 e 20 minutos no ácido sulfúrico tiveram a maior porcentagem de germinação $(85,33 \% \mathrm{em}$ ambos). Os tratamentos 1, 5, 15 e 20 minutos de imersão foram estatisticamente iguais para o índice de velocidade de germinação (IVG), o tratamento sem aplicação de ácido sulfúrico foi estatisticamente inferior aos demais tratamentos. Observou-se que tanto para a taxa de germinação, quanto para o IVG,

Tabela 1 - Variações na germinação de sementes de Mimosa pudica em função do tempo de imersão em ácido sulfúrico

\begin{tabular}{ccc}
\hline Tempo $(\mathrm{min})$ & Germinação $(\%)$ & IVG \\
\hline 0 & $25,33 \mathrm{c}$ & $3,93 \mathrm{c}$ \\
1 & $82,67 \mathrm{a}$ & $13,40 \mathrm{a}$ \\
5 & $81,33 \mathrm{a}$ & $13,16 \mathrm{a}$ \\
10 & $62,67 \mathrm{~b}$ & $10,11 \mathrm{~b}$ \\
15 & $85,33 \mathrm{a}$ & $13,54 \mathrm{a}$ \\
20 & $85,33 \mathrm{a}$ & $14,00 \mathrm{a}$ \\
CV $(\%)$ & 8,75 & 9,51 \\
\hline
\end{tabular}

Médias seguidas de mesma letra na coluna, não diferem entre si pelo teste de Tukey $(\mathrm{p}>0,05)$. todos os tratamentos promoveram resultados superiores ao tempo 0 .

Existem referências na literatura em relação ao uso do ácido sulfúrico para quebra de dormência das sementes (Azania et al., 2009; Lacerda et al., 2010), a exemplo de Torres et al. (2016) que obtiveram maior porcentagem de germinação na espécie forrageira Brachiaria ruziziensis testando ácido sulfúrico $98 \%$ por 15 min. De acordo Ferraresi et al. (2009), a maior germinação após tratamento químico das sementes, pode estar relacionado ao fato da dormência estar relacionada a impermeabilidade do tegumento. O que pode ser justificado pela dificuldade da entrada de água e gases que são imprescindíveis para estimular a germinação.

Os valores de germinação e de IVGs foram estatisticamente iguais para todos os tratamentos de sementes imersas em hipoclorito de sódio (Tabela 2). No entanto, os tratamentos com imersão de sementes durantes 2 e 8 horas, apresentaram maiores taxas de germinação cerca de $4,56 \%$ e $4,43 \%$ respectivamente. Para o IVG os maiores valores foram verificados quando as sementes foram imersas durante 4 e 8 horas com valores de 1,81 e 1,84, respectivamente. Porém, não foi possível detectar a viabilidade do hipoclorito de sódio na quebra de dormência das sementes de $M$. pudica. Ferraressi et al, (2009) observaram que o tratamento com hipoclorito de sódio promoveu a germinação de sementes de Murdannia nudiflora, porém os valores foram inferiores aos obtidos no tratamento com ácido sulfúrico.

Tabela 2 - Germinação e índice de velocidade de geminação (IVG), de sementes de Mimosa pudica, em função do tempo de imersão em hipoclorito de sódio

\begin{tabular}{ccc}
\hline Tempo $(\mathrm{h})$ & Germinação $(\%)$ & IVG \\
\hline 0 & $4,37 \mathrm{a}$ & $1,77 \mathrm{a}$ \\
1 & $4,12 \mathrm{a}$ & $1,69 \mathrm{a}$ \\
2 & $4,56 \mathrm{a}$ & $1,77 \mathrm{a}$ \\
4 & $4,38 \mathrm{a}$ & $1,81 \mathrm{a}$ \\
8 & $4,43 \mathrm{a}$ & $1,84 \mathrm{a}$ \\
12 & $3,32 \mathrm{a}$ & $1,46 \mathrm{a}$ \\
16 & $4,22 \mathrm{a}$ & $1,79 \mathrm{a}$ \\
CV $(\%)$ & 11,03 & 13,09 \\
\hline
\end{tabular}

Médias seguidas de mesma letra, minúscula na coluna, não diferem entre si pelo teste de Tukey $(\mathrm{p}>0,05)$. Dados transformados para $(\mathrm{X}+0.5)^{0.5}$. 


\section{Luz e temperatura}

A maior porcentagem de germinação foi obtida quando as sementes foram submetidas à temperatura de $25{ }^{\circ} \mathrm{C}$, de forma que houve diferença entre os tratamentos 25 e $35^{\circ} \mathrm{C}$ como fotoperíodo $12 / 12$ horas (Tabela 3). Contudo, os tratamentos $30 \mathrm{e} 35^{\circ} \mathrm{C}$ apresentaram as menores porcentagens de germinação. Quanto aos resultados de IVG, houve comportamento semelhante aos verificados para os dados de taxa de germinação, sendo no tratamento $25^{\circ} \mathrm{C}$ verificado o maior valor, e nos tratamentos 30 e $35^{\circ} \mathrm{C}$ os menores IVGs.

Resultados semelhantes foram observados por Parreira et al. (2011) na germinação de Momordica charantia, Dias et al. (2009) na germinação de trapoeraba (Commelina benghalensis), planta daninha muito problemática em canaviais e Yamashita et al. (2009) na germinação de Emilia sonchifolia. Onde observaram maiores valores de germinação e IVG na temperatura de $25^{\circ} \mathrm{C}$, sugerindo ser a temperatura mais adequada ao desenvolvimento dessas espécies.

De acordo com Machado Neto et al. (2006 b) cada espécie apresenta diferença quanto a sensibilidade a temperatura e isso pode ocorrer mesmo entre cultivares, podendo apresentar diferentes comportamentos na mesma temperatura.

Com relação às diferentes temperaturas com fotoperíodo de $08 / 16$ horas em que as sementes foram submetidas (Tabela 4), observou-se que as temperaturas de 20,30 e $35^{\circ} \mathrm{C}, 20 / 30^{\circ} \mathrm{C}$ e $20 / 35^{\circ} \mathrm{C}$, não afetaram significativamente os valores de germinação das sementes, de maneira que a menor média de germinação

Tabela 3 - Germinação e índice de velocidade de geminação (IVG), de sementes de Mimosa pudica, mantidas sob diferentes temperaturas e fotoperíodo 12/12 horas (diurna/noturna), após imersão por $15 \mathrm{~min}$ em ácido sulfúrico

\begin{tabular}{ccc}
\hline Tempo $(\mathrm{h})$ & Germinação $(\%)$ & IVG \\
\hline 20 & $94,00 \mathrm{a}$ & $15,43 \mathrm{a}$ \\
25 & $98,50 \mathrm{a}$ & $15,89 \mathrm{a}$ \\
30 & $89,00 \mathrm{ab}$ & $10,99 \mathrm{~b}$ \\
35 & $74,50 \mathrm{~b}$ & $12,38 \mathrm{~b}$ \\
$20 / 30$ & $94,50 \mathrm{a}$ & $15,75 \mathrm{a}$ \\
$20 / 35$ & $95,00 \mathrm{a}$ & $15,79 \mathrm{a}$ \\
CV $(\%)$ & 10,03 & 10,42 \\
\hline
\end{tabular}

Médias seguidas de mesma letra, minúscula na coluna, não diferem entre si pelo teste de Tukey $(\mathrm{p}<0,05)$. foi verificada no tratamento com a temperatura alternada $20 / 30^{\circ} \mathrm{C}$. Entretanto, o melhor tratamento obtido foi com a temperatura de $25^{\circ} \mathrm{C}$. Para o IVG as temperaturas $25,30,35^{\circ} \mathrm{C}$ e alterada de $20 / 35^{\circ} \mathrm{C}$ foram estatisticamente semelhantes e superiores a temperaturas constantes de 20 e alternada $20 / 30^{\circ} \mathrm{C}$.

Yamauti et al. (2012) ao estudar o efeito dos fatores ambientais sobre a germinação de agriãozinho (Synedrellopsis grisebachii) observaram que em dias mais curtos, com 8 horas de luz, a maior germinação ocorreu em temperaturas mais altas $\left(25 \mathrm{e} 30^{\circ} \mathrm{C}\right)$, entretanto em dias mais longos (entre 10 e 16 horas de luz) a maior germinação ocorreu sob temperaturas mais amenas (15 e $20^{\circ} \mathrm{C}$ ). Resultados semelhantes foram observados nesse trabalho, onde em dias mais longos (fotoperíodo $12 / 12$ ) as maiores porcentagens de germinação foram encontradas em temperaturas mais baixas, já temperaturas superiores $\left(30 \mathrm{e} 35^{\circ} \mathrm{C}\right)$ promoveram menores taxas de germinação. Porém em dias mais curtos (fotoperíodo $8 / 16$ ) observou-se que temperaturas mais altas (25$35^{\circ} \mathrm{C}$ ) promoveram maiores porcentagens de germinação.

Na ausência de luz, as sementes de M. pudica apresentaram a maior média de germinação quando foram submetidas à temperatura de $25^{\circ} \mathrm{C}$. $\mathrm{O}$ tratamento $35^{\circ} \mathrm{C}$ proporcionou a menor taxa de germinação $(52.67 \%)$ (Tabela 5).

Para o IVG, observou-se que o menor índice de velocidade de germinação foi obtido a $20^{\circ} \mathrm{C}$. E semelhantemente a porcentagem de germinação obteve maior índice a $25^{\circ} \mathrm{C}$, no entanto este não diferiu estatisticamente quando comparado as alternadas 20/

Tabela 4 - Germinação e índice de velocidade de geminação (IVG), de sementes de Mimosa pudica, sob diferentes temperaturas e fotoperíodo de 08 / 16 horas (diurna/noturna), após imersão de 15 min em ácido sulfúrico

\begin{tabular}{ccc}
\hline Tempo $(\mathrm{h})$ & Germinação $(\%)$ & IVG \\
\hline 20 & $94,00 \mathrm{a}$ & $15,43 \mathrm{a}$ \\
25 & $98,50 \mathrm{a}$ & $15,89 \mathrm{a}$ \\
30 & $89,00 \mathrm{ab}$ & $10,99 \mathrm{~b}$ \\
35 & $74,50 \mathrm{~b}$ & $12,38 \mathrm{~b}$ \\
$20 / 30$ & $94,50 \mathrm{a}$ & $15,75 \mathrm{a}$ \\
$20 / 35$ & $95,00 \mathrm{a}$ & $15,79 \mathrm{a}$ \\
CV $(\%)$ & 10,03 & 10,42 \\
\hline
\end{tabular}

Médias seguidas de mesma letra, minúscula na coluna, não diferem entre si pelo teste de Tukey $(\mathrm{p}<0,05)$. 
Tabela 5 - Germinação e índice de velocidade de geminação (IVG), de sementes de Mimosa pudica, mantidas sob diferentes temperaturas e no escuro após imersão por $15 \mathrm{~min}$ em ácido sulfúrico

\begin{tabular}{ccc}
\hline Tempo $(\mathrm{h})$ & Germinação $(\%)$ & IVG \\
\hline 20 & $80,67 \mathrm{c}$ & $4,30 \mathrm{~d}$ \\
25 & $99,33 \mathrm{a}$ & $16,25 \mathrm{a}$ \\
30 & $88,00 \mathrm{~b}$ & $14,58 \mathrm{~b}$ \\
35 & $52,67 \mathrm{~d}$ & $8,67 \mathrm{~b}$ \\
$20 / 30$ & $93,33 \mathrm{ba}$ & $15,39 \mathrm{ab}$ \\
$20 / 35$ & $95,50 \mathrm{a}$ & $15,79 \mathrm{ab}$ \\
CV (\%) & 3,72 & 4,84 \\
\hline
\end{tabular}

Médias seguidas de mesma letra, minúscula na coluna, não diferem entre si pelo teste de Tukey $(\mathrm{p}<0,05)$.

$30^{\circ} \mathrm{C}$ e $20 / 35^{\circ} \mathrm{C}$. Já os índices obtidos as temperaturas de 20 e $35^{\circ} \mathrm{C}$ diferiram estatisticamente das demais temperaturas.

Para muitas espécies de plantas daninhas a luz tem sido reconhecida como um requerimento para a germinação de sementes (Black, 1969). Conforme Hilhorst e Karssen (1988) a luz está relacionada à ativação do sistema de fitocromos, o qual está ligado ao funcionamento das membranas celulares, podendo causar uma mudança no fluxo de várias substâncias nas células e de permeabilidade das membranas, contribuindo para superar a dormência. Segundo, Marcos Filho, (2005), a sensibilidade da semente ao efeito da luz pode mudar conforme a intensidade luminosa, a qualidade e o tempo de irradiação, assim como de acordo com o período e a temperatura de embebição, no entanto a ação da luz é muito questionável, por haver variação nas respostas de acordo com as espécies e também numa mesma espécie e/ou mesma planta.

Existem espécies que só germinam após a exposição a períodos prolongados de luz, mesmo que estejam sob temperaturas ótimas para a germinação (Yamauti et al., 2012), para outras, a exposição rápida a luz é o bastante para que o processo germinativo seja desencadeado. Existem ainda, espécies como Momordica charantia (Parreira et al., 2011) que são indiferentes a presença de luz.

\section{pH e temperatura}

Conforme os resultados da germinação (\%) de sementes de Mimosa pudica submetidas a diferentes valores de $\mathrm{pHs}$ e temperaturas constantes e alternadas no fotoperíodo 12/12 (Tabela 6), verificou-se que a germinação foi influenciada pelo $\mathrm{pH}$ apenas na temperatura alternada $\left(20 / 30^{\circ} \mathrm{C}\right)$. Houve germinação em todas as faixas de $\mathrm{pH}$ analisadas indicando que o pH do solo pode não ser um fator limitante para a germinação de sementes da espécie.

Os resultados obtidos assemelham-se aos apresentados por Yamauti et al. (2012), ao avaliarem o efeito de soluções com diferentes $\mathrm{pH}$ 's na germinação de agriãozinho (Synedrellopsis grisebachii), estes observaram que as sementes germinaram em faixa de $\mathrm{pH}$ de 3,0 a 11 .

Ao analisar o efeito de cada temperatura nos diferentes $\mathrm{pH}$ 's, nota-se que temperaturas acima ou abaixo de $25^{\circ} \mathrm{C}$ causaram redução na porcentagem de germinação em todas as faixas de $\mathrm{pH}$ avaliadas. Estas reduções foram na ordem de $12,11,5$ e $18 \%$ para as temperaturas 20,30 e $35^{\circ} \mathrm{C}$, quando comparadas a temperatura de $25 \mathrm{c}^{\circ}$.

Os maiores valores de germinação foram obtidos a $25^{\circ} \mathrm{C}$, sugerindo ser a temperatura mais adequada ao desenvolvimento de Mimosa pudica. Yamashita et al. (2009) encontrou resultados semelhantes quanto a temperatura para germinação de Emilia sonchifolia em fotoperíodo de 12 h mostrando que há um alto percentual de $65 \%$ de germinação na temperatura de $25^{\circ} \mathrm{C}$.

De acordo com os dados da Tabela 6, a maior porcentagem de germinação ocorreu com o pH igual a 3 , e a temperatura de $25^{\circ} \mathrm{C}$ cerca de $99 \%$. Entretanto observou-se que a menor porcentagem de germinação ocorreu na faixa de temperatura entre $\left(20 / 30^{\circ} \mathrm{C}\right)$, no pH igual a 9 , com cerca de 67,5\%. De acordo com a literatura estudos sobre a influência do $\mathrm{pH}$ sobre a germinação de sementes de plantas daninhas ainda se encontra bastante restrito. Mas, segundo (Souza Filho et.al., 2001) não foram observadas variações de germinação de plantas daninhas como Mimosa pudica e Ipomoea asarifolia em relação ao pH.

O IVG em fotoperíodo 12/12 (Tabela 7), apresentou comportamento semelhante ao observado para a germinação. Os resultados encontrados para o pH 5 influenciou o IVG apenas nas temperaturas alternadas, apresentando um decréscimo na velocidade de germinação de cerca de $32 \%$ em relação ao $\mathrm{pH} 7$. Os maiores valores de IVG foram obtidos na temperatura 
Tabela 6 - Germinação (\%) de sementes de Mimosa pudica submetidas em diferentes gradientes de pHs, sob temperaturas constantes e alternadas e fotoperíodo 12/12 horas (diurna/noturna)

\begin{tabular}{lcccrr}
\hline & \multicolumn{5}{c}{ Temperatura $\left({ }^{\circ} \mathrm{C}\right)$} \\
\cline { 2 - 5 } & 20 & 25 & 30 & 35 & $20 / 30$ \\
\hline 3 & $14,20 \mathrm{Aab}$ & $16,00 \mathrm{Aa}$ & $14,83 \mathrm{Aa}$ & $13,54 \mathrm{Aab}$ & $11,25 \mathrm{Bb}$ \\
5 & $14,91 \mathrm{Aab}$ & $16,23 \mathrm{Aa}$ & $14,68 \mathrm{Aab}$ & $13,87 \mathrm{Aab}$ & $9,75 \mathrm{Bc}$ \\
7 & $14,42 \mathrm{Aa}$ & $16,34 \mathrm{Aa}$ & $15,71 \mathrm{Aa}$ & $14,22 \mathrm{Aa}$ & $14,50 \mathrm{Aa}$ \\
9 & $14,46 \mathrm{Aa}$ & $15,14 \mathrm{Aa}$ & $14,27 \mathrm{Aa}$ & $14,68 \mathrm{Aa}$ & $10,25 \mathrm{Bb}$ \\
11 & $15,52 \mathrm{Aab}$ & $16,09 \mathrm{Aa}$ & $14,17 \mathrm{Aab}$ & $14,84 \mathrm{Aab}$ & $12,75 \mathrm{ABb}$ \\
\hline
\end{tabular}

Letras maiúsculas iguais nas colunas e minúsculas iguais nas linhas não diferem estatisticamente entre si pelo teste de Tukey a $5 \%$ de probabilidade.

Tabela 7 - Índice de Velocidade de Germinação (IVG) de sementes de Mimosa pudica submetidas a diferentes valores de pHs e temperaturas constantes e adernadas, avaliadas em fotoperíodo 12/12

\begin{tabular}{ccccrr}
\hline & \multicolumn{5}{c}{ Temperatura $\left({ }^{\circ} \mathrm{C}\right)$} \\
\cline { 2 - 6 } & 20 & 25 & 30 & 35 & $20 / 30$ \\
\hline 3 & $14,20 \mathrm{Aab}$ & $16,00 \mathrm{Aa}$ & $14,83 \mathrm{Aa}$ & $13,54 \mathrm{Aab}$ & $11,25 \mathrm{Bb}$ \\
5 & $14,91 \mathrm{Aab}$ & $16,23 \mathrm{Aa}$ & $14,68 \mathrm{Aab}$ & $13,87 \mathrm{Aab}$ & $9,75 \mathrm{Bc}$ \\
7 & $14,42 \mathrm{Aa}$ & $16,34 \mathrm{Aa}$ & $15,71 \mathrm{Aa}$ & $14,22 \mathrm{Aa}$ & $14,50 \mathrm{Aa}$ \\
9 & $14,46 \mathrm{Aa}$ & $15,14 \mathrm{Aa}$ & $14,27 \mathrm{Aa}$ & $14,68 \mathrm{Aa}$ & $10,25 \mathrm{Bb}$ \\
11 & $15,52 \mathrm{Aab}$ & $16,09 \mathrm{Aa}$ & $14,17 \mathrm{Aab}$ & $14,84 \mathrm{Aab}$ & $12,75 \mathrm{ABb}$ \\
\hline
\end{tabular}

de $25^{\circ} \mathrm{C}$. De acordo com Kraemer et al. (2000) a temperatura ideal para a germinação da maioria das espécies encontrase entre $20-30^{\circ} \mathrm{C}$, sendo que, tanto, abaixo quanto acima destas temperaturas pode-se observar diminuição na velocidade do processo e também no total de germinação.

\section{CONCLUSÕES}

Sementes mantidas em ácido sulfúrico $\left(\mathrm{H}_{2} \mathrm{SO}_{4}\right)$ por 15 minutos apresentaram maiores teores de germinação e IVG, com $85,33 \%$ e 13,54 respectivamente.

O hipoclorito de sódio não atuou na quebra de dormência de sementes de Mimosa. pudica.

A temperatura na qual houve maior germinação de sementes de Mimosa pudica obtida em ambos os fotoperíodos e no escuro foi $25^{\circ} \mathrm{C}$ e que a espécie é fotoblástica neutra.

Não foram observadas variações de germinação de Mimosa pudica em relação ao pH.

O estudo da influência dos fatores abiótico na germinação da planta daninha Mimosa pudica, contribui efetivamente com as táticas de manejo desta espécie em áreas de cultivo.

\section{LITERATURA CITADA}

BASTIANI, M.O.; LAMEGO, F.P.; NUNES, J.P.; MOURA, D.S.; WICKERT, R.J.; OLIVEIRA, J.I. Germinação de sementes de capim-arroz submetidas a condições de luz e temperatura. Planta Daninha, Viçosa-MG, v. 33, n. 3, p. 395 404, 2015.

BLACK, M. Light-controlled germination of seed. Symposia of the Society for Experimental Biology, v.23, p. 193, 1969.

BRASIL. Ministério da Agricultura, Pecuária e Abastecimento. Regras para análise de sementes. Ministério da Agricultura, Pecuária e Abastecimento. Secretaria de Defesa Agropecuária, 2009. 395p.

CANOSSA, R.S.; OLIVEIRA JUNIOR, R.S.; CONSTANTIN, J.; BIFFE, D.F.; ALONSO, D.G.; FRANCHINI, L.H.M. Profundidade de semeadura afetando a emergência de plântulas de Alternanthera tenella. Planta Daninha, v. 25, p. 719-725, 2007a. 
CARVALHO, N.M.; NAKAGAWA, J. Sementes: ciência, tecnologia e produção. 5 ed. Jaboticabal: FUNEP, 2012. 588p.

CHACHALIS, D.; REDDY, K. N. Factors affecting Campsis radicans seed germination and seedling emergence. Weed Science, v. 48, p. 212-216, 2000.

CHAUHAN, B. S.; JOHNSON, D. E. Germination ecology of Spiny (Amaranthus spinosus) and Slender Amaranth (A. viridis): troublesome weeds of direct seeded rice. Weed Science, v. 57, n. 4, p. 379-385, 2009.

DIAS, A. C. R.; CARVALHO, S. J. P.; BRANCALION, P. H. S.; NOVEMBRE, A. D. L. C.; CHRISTOFFOLETI, P. J. Germinação de sementes aéreas pequenas de trapoeraba (Commelina benghalensis). Planta Daninha, v. 27, n., p. 931939, 2009.

DURAN, R.D.; TORTOSA, M.E. The effect of mechanical and chemical scarification on germination of charlock (Sinapis arvensis L.) seeds. Seed Science Technology, v.13, n.1, p.155$163,1985$.

FERRARESI, D. A.; YAMASHITA, O. M.; CARVALHO, M. A. C. Superação da dormência e qualidade de luz na germinação de sementes de Murdannia nudiflora (L.) Brenans. Revista Brasileira de Sementes, vol. 31, n. 4, p.126-132, 2009.

FERREIRA, D.F. Sistema de análises de variância para dados balanceados. Lavras: UFLA, 2014.

GAZOLLA-NETO, A.; CORREA, M. F.; GOMES, A. D.; GADOTTI, G. I.; VILLELA, F. A.

Distribuição espacial da qualidade fisiológica de sementes de soja em campo de produção. Revista Caatinga, v. 28, n. 3, p. 119-127, 2015.

GUILLEMIN, J.P. et al. Assessing potential germination period of weeds with base temperatures and base water potentials. Weed Research, v. 53, n. 1, p. 76-87, 2013.

HILHORST, H.W.M. \& KARSSEN, C.M. Dual effect of light on the gibberellin- andnitratestimulated seed germination of Sisymbrium officinale and Arabidopsis thaliana. Plant Physiology, v. 86, p. 591-597, 1988.
JARRETA JR, O.; SEGATO, S. V. Germinação de sementes de Chloris polydactyla em diferentes temperaturas e condições de luminosidade. Nucleus, v.13, n.1, 2016.

KRAEMER, K.H.; KAMPF, A.N.; ÁQUILA, M.E. Luz e temperatura na germinação de sementes de Tibouchina urvilleana. Revista Brasileira de Horticultura Ornamental, v.6, n.1/2, p.39-45, 2000.

LACERDA, M. J. R.; CABRAL, J. S. R.; SALES, J. F.; FREITAS, K. R.; FONTES, A. J. Superação da dormência de sementes de Brachiaria brizantha cv. "Marandu". Semina, v.31, n.4, p.823-828, 2010.

MACHADO NETO, N. B.; PRIOLI, M. R.; GATTI; A. B.; CARDOSO; V. J. M. Efeitos da temperatura na germinação de sementes em culturas de feijões comuns (Phaseolusvulgaris L.). Acta Scientiarum, v. 28, n. 2, p. 155-164, 2006 b.

MAGUIRE, J. D. Speed of germination-aid in selection and evaluation for seedling emergence and vigor. Crop Science, Madison, v. 2, n. 1, p. 176-177, 1962.

MARCOS FILHO, J. Fisiologia de sementes de plantas cultivadas. Piracicaba: FEALQ, 2005.

MAYEUX, H.S.; SCIFRES, C.J. Germination golden weed seed. Journal of Range Management, v.31, p.371-374, 1978.

MONDO, V. H. V.; CARVALHO, S. J. P.; DIAS, A. C. R.; MARCOS FILHO, J. Efeitos da luz e temperatura na germinação de sementes de quatro espécies de plantas daninhas do gênero Digitaria. Revista Brasileira de Sementes, v. 32, n. 1, p.131-137, 2010.

MONQUERO, P. A.; HIJANO, N.; ORZARI, I.; SABBAG, R. S.; HIRATA, A. C. S. Profundidade de semeadura, $\mathrm{pH}$, textura e manejo da cobertura do solo na emergência de plântulas de Rottboellia exaltata. Semina: Ciências Agrárias, v. 33, n. 1, p. 2799-2812, 2012.

NANDULA, V. K.; EUBANK, T. W.; POSTON, D. H.; KOGER, C. H.; REDDY, K. N. Factors affecting germination of horse weed (Conyza canadensis). Weed Science, v. 54, n. 5, p. 898- 
902, 2006.

ORZARI, I.; MONQUERO, P.A.; REIS, F.C.; SABBAG, R.S.; HIRATA, A.C.S. Germinação de espécies da família Convolvulaceae sob diferentes condições de luz, temperatura e profundidade de semeadura. Planta Daninha, v. 31, n. 1, p. 53-61, 2013.

PARREIRA, M. C.; CARDOZO, N. P.; GIANCOTTI, P. R. F.; ALVES, P. L. A. C.

Germinação de sementes de melão-de-são-caetano sob variação de água, luz e temperatura.

Bioscience Journal, v. 27, n. 3, p. 363-370, 2011.

PAULA, C. S. Controle químico de Mimosa pudica em pastagem de Brachiaria decumbens com doses reduzidas de herbicidas. Dissertação (mestrado). Ilha Solteira, SP: UNESP, 2013.37p.

RONCHI, C.P.; SERRANO, L.A.L.; SILVA. A.A.; GUIMARÃES, O.R. Manejo de plantas daninhas na cultura do tomateiro. Planta Daninha, v. 28, n.
1, p. 215-228, 2010.

SOUZA FILHO, A.P.S.; ALVES, S.M.; FIGUEIREDO, F.J.C.; DUTRA, S. Germinação de sementes de plantas daninhas de pastagens cultivadas: Mimosa pudica e Ipomoea asarifolia. Planta Daninha, v. 19, n. 1, p. 23-31, 2001.

TORRES, F. E.; ANDERSON, J. P.; TEODORO, P. E.; RIBEIRO, L. P.; CORRÊA, C. G.; SILVA, F. A. Eficiência de tratamentos químicos e térmico na quebra de dormência de três espécies de Brachiaria. Revista de Ciências Agrárias, v. 39, n. 2, p. 210-215, 2016.

YAMASHITA, O. M.; GUIMARÃES, S. C.; SILVA, J. L.; CARVALHO, M. A. C.; CAMARGO, M. F. Fatores ambientais sobre a germinação de Emilia sonchifolia. Planta daninha, v. 27, n. 4, p. 673$681,2009$.

YAMAUTI, M. S.; PAVANI, M. C. M. D.; ALVES, P. L. C. A.; MORO, F. V. Efeito de fatores ambientais sobre a germinação de agriãozinho (Synedrellopsis grisebachii). Científica, v.40, n.2, p. 150-155, 2012.

Recebido para publicação em 07/01/2019 e aprovado em 21/06/2019. 